\title{
Nanoparticles Transport in Ceramic Matrices: A Novel Approach for Ceramic Matrix Composites Fabrication
}

\author{
Andrey N. Rybyanets, Anastasia A. Naumenko \\ Southern Federal University, Rostov on Don, Russia \\ Email: arybyanets@gmail.com
}

Received March 12, 2013; revised April 19, 2013; accepted June 5, 2013

Copyright (C) 2013 Andrey N. Rybyanets, Anastasia A. Naumenko. This is an open access article distributed under the Creative Commons Attribution License, which permits unrestricted use, distribution, and reproduction in any medium, provided the original work is properly cited.

\begin{abstract}
The results of practical implementation of a new method for porous piezoceramics, and ceramic matrix piezocomposites fabrication were presented. The method was based on nanoparticles transport in ceramic matrices using a polymer nanogranules coated or filled with a various chemicals, with successive porous ceramics fabrication processes. Different types of polymer microgranules filled and coated by metal-containing nanoparticles were used for a pilot samples fabrication. Polymer microgranules were examined using transmission and scanning electron microscopy as well as by EXAFS and X-ray emission spectroscopy. Pilot samples of nano- and microporous ceramics and composites were fabricated using different piezoceramics compositions (PZT, lead potassium niobate and lead titanate) as a ceramic matrix bases. Resulting ceramic matrix piezocomposites were composed by super lattices of closed or open pores filled or coated by nanoparticles of metals, oxides, ferromagnetics etc. embedded in piezoceramic matrix. Dielectric and piezoelectric parameters of pilot samples were measured using piezoelectric resonance analysis method. New family of nanoand microporous piezoceramics and ceramic matrix piezocomposites are characterized by a unique spectrum of the electrophysical properties unachievable for standard PZT ceramic compositions and fabrication methods.
\end{abstract}

Keywords: Nanoparticles; Polymer Nanogranules; Porous Ceramics; Ceramic Matrix Composites

\section{Introduction}

In recent years, multiphase ceramic composites (nanocomposites, porous ceramics, composites ceramics/ceramics, and ceramics/crystals) are widely used for industrial and ultrasonic transducers applications [1-4]. Numerous technologies based on incorporating of nano quantities of functional ceramics into structural ones and vice-versa have been developed and the novel design idea has been applied in the field of functional ferroelectric ceramics $[2,5]$.

Nanoparticles are perfect building blocks offering a wide variety of compositions, structures and properties, ideally suited to designing functional nanomaterials and nanodevices. Nanoparticles can be embedded in various matrixes. A major technological problem is spontaneous aggregation of nanoparticles which, as a result, lose their unique properties. One possible solution to this problem is to use supports interacting with nanoparticles. Many organic polymers have been used in various nanoparticle surface engineering approaches [6].

Recently polymer nano and microgranules filled with nanoparticles (magnetic, metal, oxides etc.) start widely used as a delivery means of nanosubstances in medical, biotechnology and chemical applications [7]. Very recently, there was a tendency to fix (immobilize) $2-10$ $\mathrm{nm}$ particles on the surface of spherical polymeric microgranules (typically $0.1-20 \mu \mathrm{m}$ in size) $[8,9]$. Such composite micro-nano systems offer a number of significant advantages. When fixed to a surface or embedded in microgranules, nanoparticles loose their tendency to readily aggregate but retain their reactivity and, for the most part, their physical properties. Besides, microgramules are easier to manipulate then nanoparticles. Microgranules, coated or filled with nanoparticles can be used to produce "homogeneous" disperse systems, such as sols and aerosols, and fabricate films, coatings or bulk materials. The preparation and properties of microgramules for different applications as well as the properties of particular types of nanoparticles were described elsewhere [6-9].

Intensive research and technological works as well as improvements of fabrication methods have allowed 
large-scale manufacture of porous piezoelectric ceramics with reproducible and controllable porosity and properties $[5,10,11]$. Closed cell porous ceramics are usually formed by adding porosifiers to ceramics powders (burnable plastic spheres) [5]. An universal manufacturing method suitable for mass production of a wide class of nano and microporous piezoceramics and ceramic matrix piezocomposites (CMPC) was described in $[5,12$, 13].

In this paper we propose a novel approach for fabrication of nano- and microporous piezoceramics as well as CMPC. The technique is based on nanoparticles transport in ceramic matrices using polymer nano- and microgramules coated or filled by nanoparticles of various chemicals, with successive porous ceramics fabrication processes.

\section{Nanoparticles Transport Concept}

\section{Selecting a Template}

The nanoparticles transport concept (NPT) proposed in this paper is a nontrivial combination of manufacture technologies of porous ceramics and ceramic matrix composites [12,13] and microcapsules transport techniques used in biomedical applications for targeting nanoparticles drugs delivery [6].

Over the past years, considerable advances were made to improve the physical, electrical and functional properties of piezoelectric ceramics using composite approaches [5]. Numerous composite technologies were developed and a novel design ideas was applied to develop functional piezoelectric ceramics $[2,12,13]$.

The original microstructural design concept (MSD) for ceramic matrix composites was proposed in [2]. The MSD concept offers a brand-new range of polymer-free piezocomposite materials with parameters that are adjustable over a wide range. The MSD concept is based on controllable substitution during composite formation of separate crystallites or crystallite groups making a polycrystal by pores, crystallites with other composition and/or structure, or amorphous substances, all with preliminary choice of chemically, thermally and technologically compatible components and with FEM modeling of polycrystalline composite properties. The distinctive peculiarities of the MSD concept is the transition to a micro- or nanoscale level of separate crystallites and the use of the full set of technological approaches at particular stages of synthesis, preparation of initial materials (powders, solutions, suspensions, gels), granulation and compacting of a green bodies, sintering and the-post sintering treatment of a composites.

The MSD concept offers an innovative range of polymer-free piezocomposite materials (micro-, mesa- and macroporous piezoelectric ceramics, piezocomposites ceramics/ceramics and ceramic/crystal, and CMPC) with properties combining better parameters for PZT, PMN, $\mathrm{PN}$ and PT type ceramics and $1-3$ composites $[4,10,13]$.

Porous piezoceramic is composite material composed of two phases: a piezoelectrically active (piezoceramic) phase and a passive (porous) phase. The piezoelectrically active phase forms a three-dimensional matrix, in which the passive phase exists in the form of isolated and/or interconnected inclusions. The case of isolated inclusions corresponds to 3-0 connectivity while the intercomnected inclusions case, to 3-3 connectivity type (closed and open porosity, respectively) [12]. The microstructure of porous ceramics is unequivocally defined by the fabrication method and by the initial chemical composition of the piezoceramic phase. The structure and properties of porous ceramics are controlled by their processing.

Figure 1 shows micrographs illustrating the margimal cases of a micro-structural variety of porous ceramic materials. The resulting elastic, dielectric, and piezoelectric properties of porous piezoceramics are defined by the properties of its piezoceramic matrix: that is, the porosity, type of connectivity, shape, and size of pores (and, in the case of irregular shaped pores, by the degree of their primary orientation and arising anisotropy) $[5,10,12]$.

All existing methods of porous ceramics fabrication can be divided into two basic approaches: subtractive processes and processing limitations. In subtractive processes, certain elements of an original structure are selectively removed to create pores. In processing limitations, technological processing regimes are modified to form porous structures [12]. Porous ceramics with an open cell structure are usually formed by replicating a polymer foam/sponge. Closed cell porous ceramics are usually formed by adding porosifiers to ceramics powders.

A simpler technique for production of highly porous compacts was proposed in [11] with sintered mixtures of burnable plastic spheres (PMMA) and PZT powders. A series of further process for the preparation of porous ceramics and composites with 3-3 connectivity were

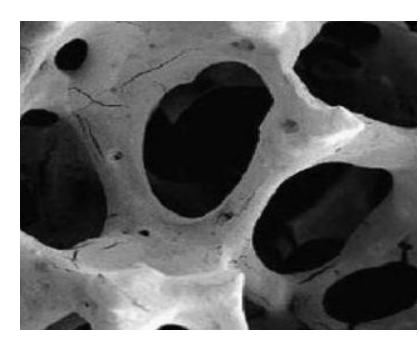

(a)

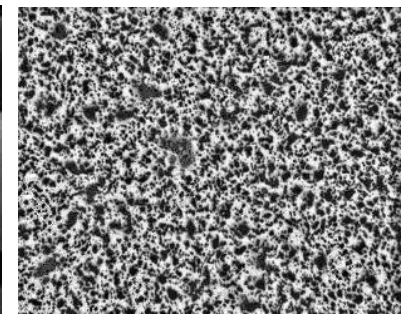

(b)
Figure 1. SEM micrographs of different porous ceramics structures: (a) open cell PZT ceramics, fabricated by polymer foam method; (b) closed cell PZT ceramics, obtained by burning out polymer granules. 
subsequently introduced [2,10,12].

The universal manufacturing method suitable for mass production of a wide range of porous piezoceramics and piezocomposite materials based on burning out of burnable particles (polymer, organic substances or salts) proposed in $[5,12]$ was used in the NPT concept.

Nanoparticles transport techniques using microgramules or microcapsules as a delivery means are intensively developed and widely used now for targeting drugs delivery and other biomedical and chemical applications $[6,7]$. A fabrication techniques of polymer microgranules coated or filled (microcapsules) by nanoparticles of a various chemicals are well developed and different types of microgranules are commercially available [6]. The preparation and properties of microgranules for different applications as well as the properties of particular types of nanoparticles were described elsewhere [6-9].

In the NPT method, proposed in this paper, polymer nano- and microgranules coated or filled with nanoparticles of various chemicals are used as a porosifier agents for modified porous ceramics fabrication process. Thereby, polymer nano- and microgranules act as a delivery means for targeting transport of nanosubstances into ceramic matrixes with closed nanopores.

The NPT concept comprises:

- nanoparticles, nano- and microgranules preparation;

- filing or coating of nano- and microgranules with nanoparticles;

- characterization of the nanoparticles and microgramules;

- porous ceramics and CMPC fabrication process;

- resulting porous ceramics aor CMPC characterization. The full scale use of the NPT concept will results in a new generation of nano- and microporous ceramics and composite materials derived from technologically simple processing, whilst offering an unique combination of piezoelectric, magnetic and electrets properties along with a possibility of controllable changes of the main properties.

\section{Experimental Scenario}

\subsection{Polymer Microgranules and Nanoparticles Preparation}

Four types of polymer microgranules were used for "pilot" porous ceramics and CMPC samples fabrication:

- pure polystyrene microgranules (PS); polystyrene microgranules (PS) filled with magnetite $\left(\mathrm{FeO} \cdot \mathrm{Fe}_{2} \mathrm{O}_{3}\right)$ and $\mathrm{NiO}$ nanoparticles;

- pure polytetrafluoroethylene nanogranules (PTFENG); and

- polytetrafluoroethylene nanogranules (PTFENG) coated with metal-containing ( $\mathrm{Fe}, \mathrm{Co}, \mathrm{Ni}, \mathrm{Cu}, \mathrm{Pt}$ and $\mathrm{Pd}$ ) nanoparticles (MCNP).
Magnetite $\left(\mathrm{FeO} \cdot \mathrm{Fe}_{2} \mathrm{O}_{3}\right)$ nanoparticles $10-40 \mathrm{~nm}$ in diameter were prepared by chemical deposition of solid phase from Fe-salts solutions. NiO nanoparticles 10 - 30 $\mathrm{nm}$ in diameter were prepared by thermal decomposition of and Ni-salts $\left(\mathrm{NiCO}_{3}\right)$. PS microgranules 80 - $100 \mathrm{~nm}$ in diameter were prepared from polystyrene/magnetite or polystyrene/NiO colloidal fluids with successive polymerization [7].

PTFENG microgranules 150 - $500 \mathrm{~nm}$ in diameter were fabricated by the thermal gas-dynamic method [8]. MCNP nanoparticles $3.5-6.5 \mathrm{~nm}$ in diameter have been synthesized and immobilized on the surface of politetrafluoroethylene nanogranules via thermal decomposition of metal-containing precursors on the surface of PTFENG in mineral oil, as described in [9].

To produce MCNP from MRn precursors $(\mathrm{M}=\mathrm{Co}, \mathrm{Fe}$, $\mathrm{Cu}, \mathrm{Ni}, \mathrm{Pd} ; \mathrm{R}=\mathrm{CO}, \mathrm{HCOO}, \mathrm{CH}_{3} \mathrm{COO}$ ), well-developed thermal decomposition processes have been used [9]. At PTFENG sizes from 100 to $500 \mathrm{~nm}$, a fluidized bed of microgranules was formed over the surface of heated oil. This behaviour of microgranules was used to immobilize MCNP. In the course of deposition, the nanogranules became progressively heavier, and some of them left the fluidized bed and settled in the oil. As a result, the MCNP on their surfaces stopped growing.

\subsection{Characterization of the Nanoparticles and Microgranules}

Polystyrene microgranules filled with magnetite or $\mathrm{Ni}$ nanoparticles were examined using transmission and scanning electron microscopy (TEM and SEM).

Figure 2 shows a typical TEM image of magnetite nanoparticles and their size distribution. Nanoparticles have average diameter $10 \mathrm{~nm}$ at size variation $9.6 \%$. Examplary micrographs of polystyrene microgranules containing magnetite nanoparticles are shown on Figure 3.

The MCNP nanoparticles were examined by X-ray diffraction (XRD), transmission and scanning electron microscopy (TEM and SEM), EXAFS spectroscopy, $\mathrm{X}$-ray emission and Moessbauer spectroscopy [8,9]. The results demonstrate that the nanoparticles with average size $3.5-6.5 \mathrm{~nm}$ have a complex structure, are isolated from one another and are strongly bonded to the surface of the nanogranules.

The metal content of the samples was determined by elemental analysis. TEM images were taken on a JEOL JEM-100B at an accelerating voltage of $100 \mathrm{kV}$.

Figure 4 shows a representative TEM image of asprepared PTF-ENG/MCNP [9].

As seen in Figure 4, MCNP are distributed rather evenly throughout the PTFENG surface. It easily to seen that all the nanogranules are covered with nearly monodisperse MCNP. 


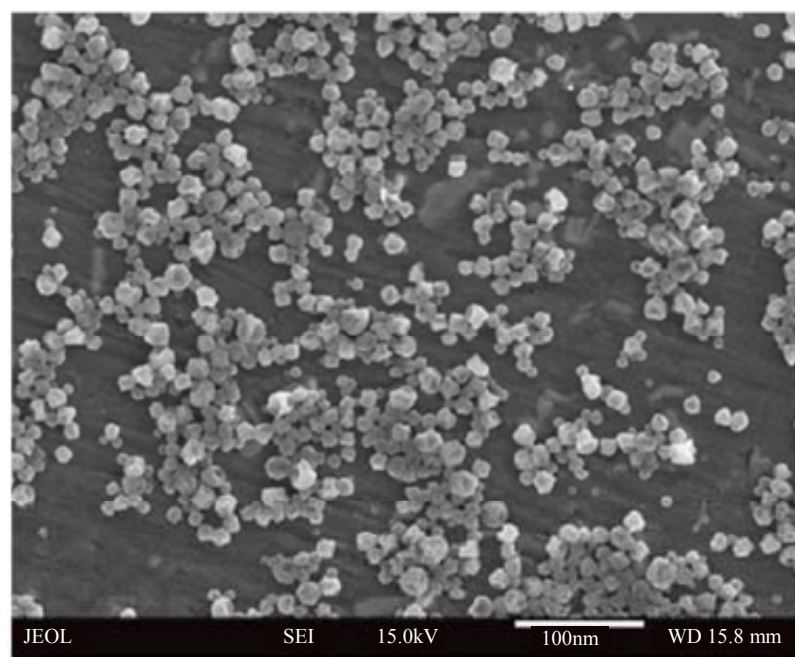

(a)

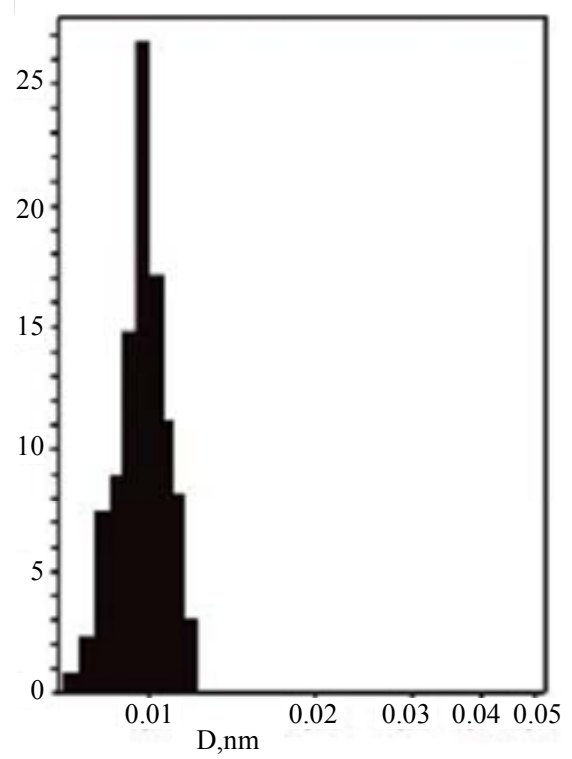

(b)

Figure 2. SEM micrographs of magnetite nanoparticles (a) and their size distribution (b).

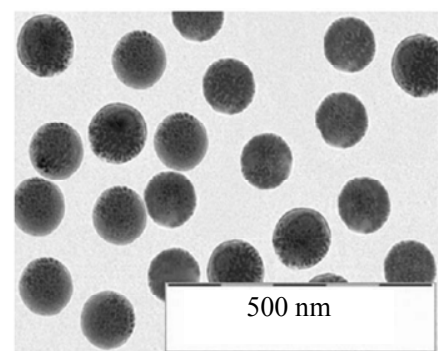

(a)

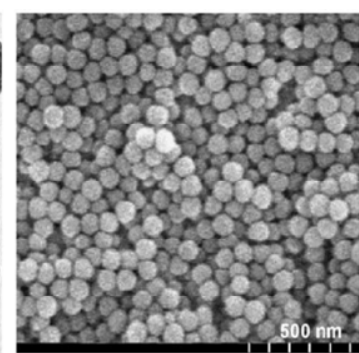

(b)
Figure 3. Micrographs of polystyrene microgranules containing magnetite nanoparticles: (a) TEM, (b) SEM. Magnetite mass content $\sim \mathbf{4 0} \%$, average diameter of microgranules $100 \mathrm{HM}$.

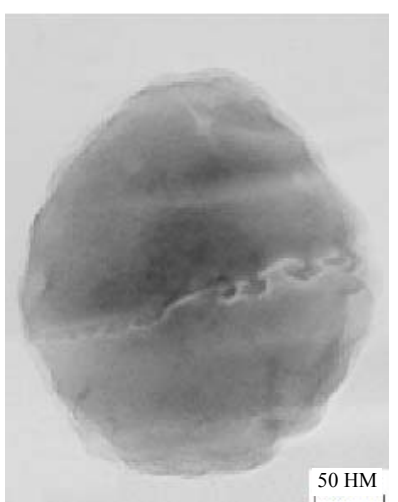

(a)

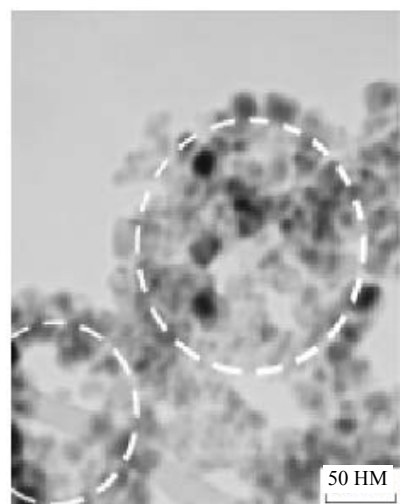

(b)

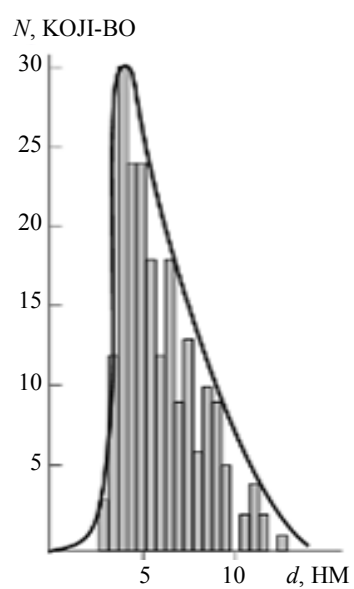

(c)

Figure 4. Examplary TEM image of initial PTFENG (a), as-prepared PTFENG/MCNP (b) and their size distribution (c).

From the TEM image in Figure 4, the average size of the MCNP $\left[\mathrm{c}-\mathrm{Fe}_{2} \mathrm{O}_{3}\right.$ prepared from $\mathrm{Fe}\left(\mathrm{CH}_{3}-\mathrm{COO}\right)_{3}$ ] was determined to be $\sim 5 \mathrm{~nm}$, with a narrow size distribution. The average sizes of $\mathrm{Ni}$ - and Pd-containing nanoparticles were 3.5 and $7.5 \mathrm{~nm}$, respectively.

Although the number of MCNP surrounding each PTFENG varied from sample to sample, we were able to control the total amount of the deposited metal per nanogranule by varying the precursor concentration in the solution.

\subsection{Porous Ceramics and CMPC Fabrication Processes}

Schematic illustration of the technological processes used for porous ceramics and CMPC fabrication are shown on Figure 5.

Standard sequence of porous ceramics technological processes (mixing, compacting, burning out and sintering) were used for CMPC fabricaton. Polymer nanogranules, coated or filled with a various chemicals, were used as as porosifier agents. Resulting CMPC were composed by 
A

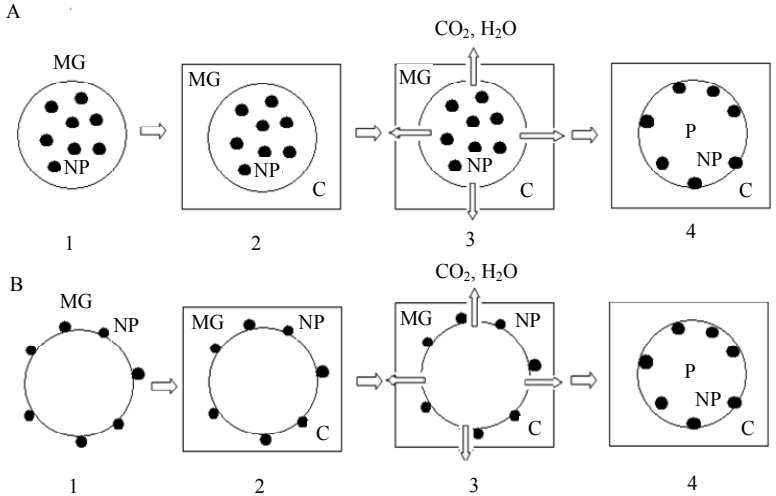

Figure 5. Schematic technological process for nano- and microporous piezoceramics and CMPC fabrication using polymer microgranules filled (A) and coated (B) with nanoparticles: 1 -preparation of microgranules (MG) filled (A) and coated (B) with nanoparticles (NP); 2 - embedding of microgranules (MG) in ceramic matrix (C) by means of mixing and compacting; 3 -burning out (thermal decomposition) of polymer microgranules (MG) and deposition of nanoparticles (NP) on a pore surface; 4 - sintering of porous ceramic matrix $(P)$ and covering internal pores surface with nanolayers of metals or oxides, local doping or modification of stoichiometric composition of surface layer of piezoceramics (C).

super lattices of closed pores filled or coated by nanoparticles of metals, oxides, ferromagnetics etc. embedded in piezoceramic matrix.

Special regimes of wet and dry mixing were used for homogeneous distribution of polymer nanogarnules in piezoceramic raw powders. Burning out was fulfilled at $700^{\circ} \mathrm{C}$ to provide full decomposition of polymer components. Sintering was carried out at optimal temperature for each piezoceramic composition.

Special anti-oxidation nanoparticles additives ( $\mathrm{SiC}$ and $\mathrm{C}$, as an examples) were be embedded in polyer nanogranules simultaneously with matall or oxide nanoparticles in proper mass proportion, to prevent undesirable oxidation of metal nanoparticles or to deoxidize metal oxides during ceramics sintering process.

\section{Experimental Results}

\subsection{Method of Measurements}

The basic techniques for finding material constants of piezoelectric materials are outlined in the IEEE Standard on Piezoelectricity (1987) [14]. These methods work for many of the most widely used commercial piezoceramics based on lead titanate-zirconate (PZT) compositions that are high-QM and high-coupling coefficient piezoelectric materials. However, there is a general agreement that their use in many new piezoelectric materials such as porous ceramics, piezoelectric polymers or piezoelectric composites may lead to significant errors. Furthermore, the current IEEE Standard does not comprehensively account for the complex nature of material coefficients, as it uses only the dielectric loss factor $(\tan \delta)$ and the mechanical quality factor $\left(\mathrm{Q}_{\mathrm{M}}\right)$ to account for loss.

Numerous techniques using complex material constants have been proposed to take into account losses in low- $\mathrm{Q}_{\mathrm{M}}$ materials and to overcome limitations in the IEEE Standard [15-18]. Iterative methods [19-21] provide a means to accurately determine the complex coefficients in the linear range of poled piezoceramics from complex impedance resonance measurements.

The Piezoelectric Resonance Analysis Program (PRAP) automatic iterative method [21] was proposed for complete complex characterization of a wide range of materials with very high and moderate loss factors. The PRAP software analyses impedance spectra to determine complex material properties. This software uses a generalized form of Smits's method to determine material properties for any common resonance mode, and a generalized ratio method for the radial mode valid for all material Q's. By analyzing on each harmonic, PRAP can determine complex material properties as a function of frequency. The software always generates an impedance spectrum from the determined properties to indicate validity of the results.

New nanoporous piezoceramics and CMPC are lossy and direct use of IEEE Standards for material constant evaluation can leads to significant errors, therefore the PRAP automatic iterative measurement method [21-23] was applied to the full set of standard geometries and resonance modes needed to complete complex characterization of the pilot samples.

Measurements of electric parameters were made using the Solartron Impedance/Gain-Phase Analyzer SL 1260 and Agilent 4294A Impedance Analyser. Pulse-echo and through-transmit measurements of ultrasonic transducers were made using LeCroy digital oscilloscope and Olympus pulser/receiver. Piezoelectric modulus was measured using APC $\mathrm{d}_{33}$ tester.The microstructure of polished, chemically etched, and chipped surfaces of composite samples was observed with optical (NeoPphot-21) and scanning electron microscopes (SEM, Karl Zeiss).

\subsection{Microstructure of Nanoporous Ceramics and CMPC}

A pilot samples of nano and microporous ceramics and CMPC were fabricated using different piezoceramics compositions (PZT, lead potassium niobate and lead titanate) as a ceramic matrix and PS and PTFENG microgranules as a porosifier agents.

Figure 6 shows SEM micrograph of grinded surface of PZT nanoporous piezoceramics prepared as a result of pure PS microgranules burning out and sintering. The 


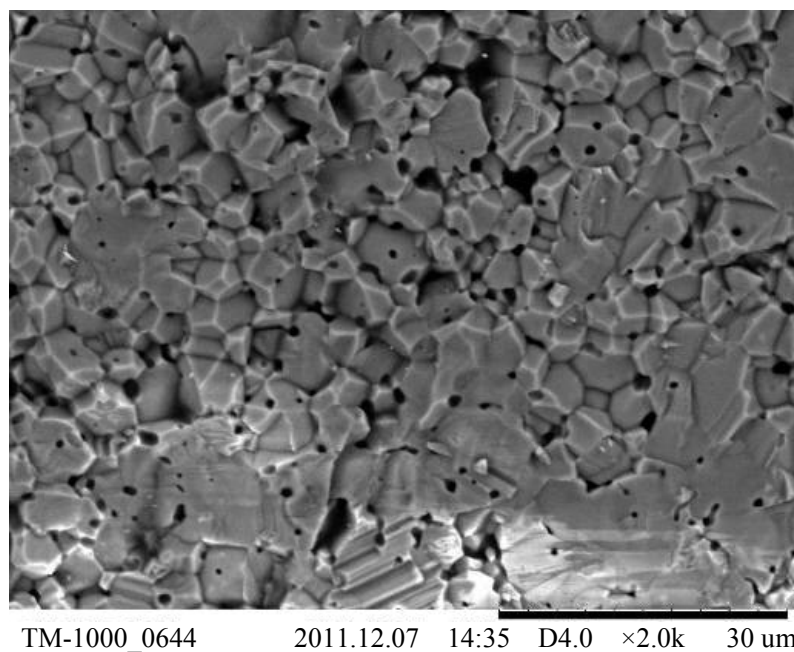

Figure 6. SEM micrograph of grinded surface of PZT piezoceramics with mixed inter- and intracrystalline nanoporosity.

resulting porous ceramics demonstrate mixed inter- and intracrystalline closed porosity. Notable variation of intra- and intercrestallite pore sizes is caused by partial agglomeration of PS microgranules during mixing and compacting processes.

Figure 7 shows SEM micrograph of chiped surface of PZT nanoporous piezoceramics prepared as a result of pure PTFENG microgranules burning out and sintering. It is obvious that PTFENG microgranules are prevent compacting of PZT powder a lead to intercrystalline nanopores formation.

Figure 8 shows optical micrograph of lead potassium niobate (PKN) ceramics microstructure with closed intracrystallite nanopores filled by magnetite nanoparticles formed as a result of PS-magnetite microgranules burning out and sintering. Resulting piezo-magnetic CMPC demonstrate notable magnetic properties at retained piezoelectric characteristics of initial PKN ceramics.

Figure 9 shows SEM micrograph of internal surface of closed pore in PZT piezoceramics covered by $\mathrm{Pd}$ nanoparticles formed as a result of PTFENG-Pd microgranules burning out and sintering.

Figure 9 clearly demonstrates a possibility of pinpoint delivery of definite number of nanoparticles into target ceramic matrix. Figure 10 shows SEM micrograph of internal surface of closed micropores in PZT piezoceramics covered by Ni nanoparticles layer (covering rate $80 \%$ ) after PS-NiO + SiC microgranules burning out and sintering.

\subsection{Dielectric and Piezoelectric Properties}

Positioning The distinctive peculiarity of a new family of nano- and microporous piezoceramics and CMPC are the possibility of controllable changes of the main properties

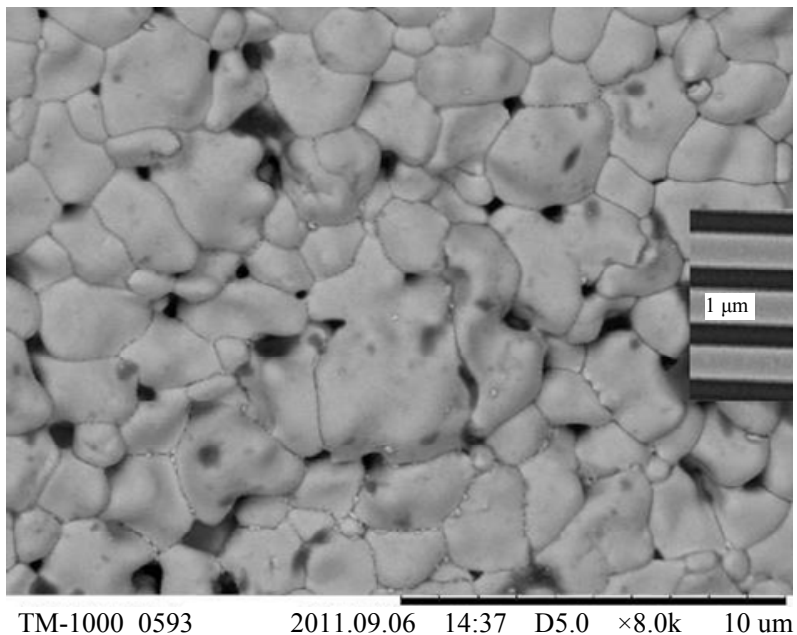

Figure 7. SEM micrograph of chipped surface of PZT nanoporous piezoceramics with closed intercrystalline nanoporosity.

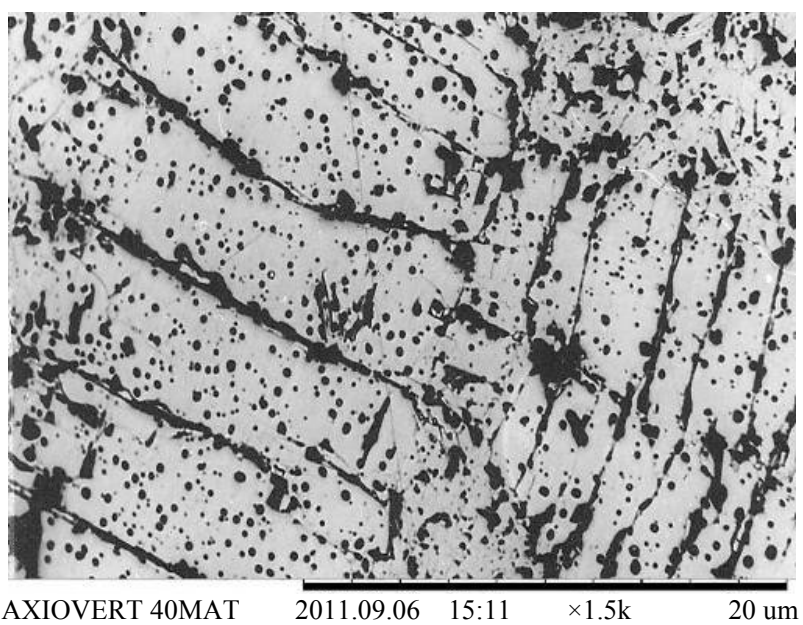

Figure 8. Optical micrograph of PKN piezoceramics with closed intracrystalline nanoporosity filled by magnetite nanoparticles.

within a wide range along with a possible combination of piezoelectric, magnetic and electrets properties:

- acoustic impedance $0.1 Z_{\mathrm{AC}} \leq \mathrm{Z}_{\mathrm{A}} \leq 2 \mathrm{Z}_{\mathrm{AK}}$, where $\mathrm{Z}_{\mathrm{AC}}$-impedance for initial ceramics;

- dielectric constant $0.1 \varepsilon_{33}{ }^{\mathrm{T}} \mathrm{C} \leq \varepsilon_{33}{ }^{\mathrm{T}} \leq 5 \varepsilon_{33}{ }^{\mathrm{T}} \mathrm{C}$, where $\varepsilon_{33}{ }^{\mathrm{T}} \mathrm{C}$ - dielectric constant for initial ceramics;

- electromechanical coupling factors $0.1 \mathrm{k}_{\mathrm{pC}} \leq \mathrm{k}_{\mathrm{p}} \leq \mathrm{k}_{\mathrm{pC}}$, $\mathrm{k}_{\mathrm{tC}} \leq \mathrm{kt} \leq 1.5 \mathrm{k}_{\mathrm{tC}}$, where $\mathrm{k}_{\mathrm{pC}}$ and $\mathrm{k}_{\mathrm{tC}}$ radial and thickness for initial ceramics;

- piezoelectric modulus $\mathrm{d}_{33 \mathrm{C}} \leq \mathrm{d}_{33} \leq 2 \mathrm{~d}_{33 \mathrm{C}}, 0.1 \mathrm{~d}_{31} \mathrm{C} \leq \mathrm{d}_{31}$ $\leq \mathrm{d}_{31 \mathrm{C}}$, где $\mathrm{d}_{33 \mathrm{C}}$ и $\mathrm{d}_{31 \mathrm{C}}$ longitudinal and thickness for initial ceramics.

Figure 11 shows impedance spectra (impedance modulus $|\mathrm{Z}|$ and phase angle $\varphi$ as function of frequency $\mathrm{f}$ ) for nanoporous PZT piezoceramics at different relative porosity $\mathrm{P}$. 


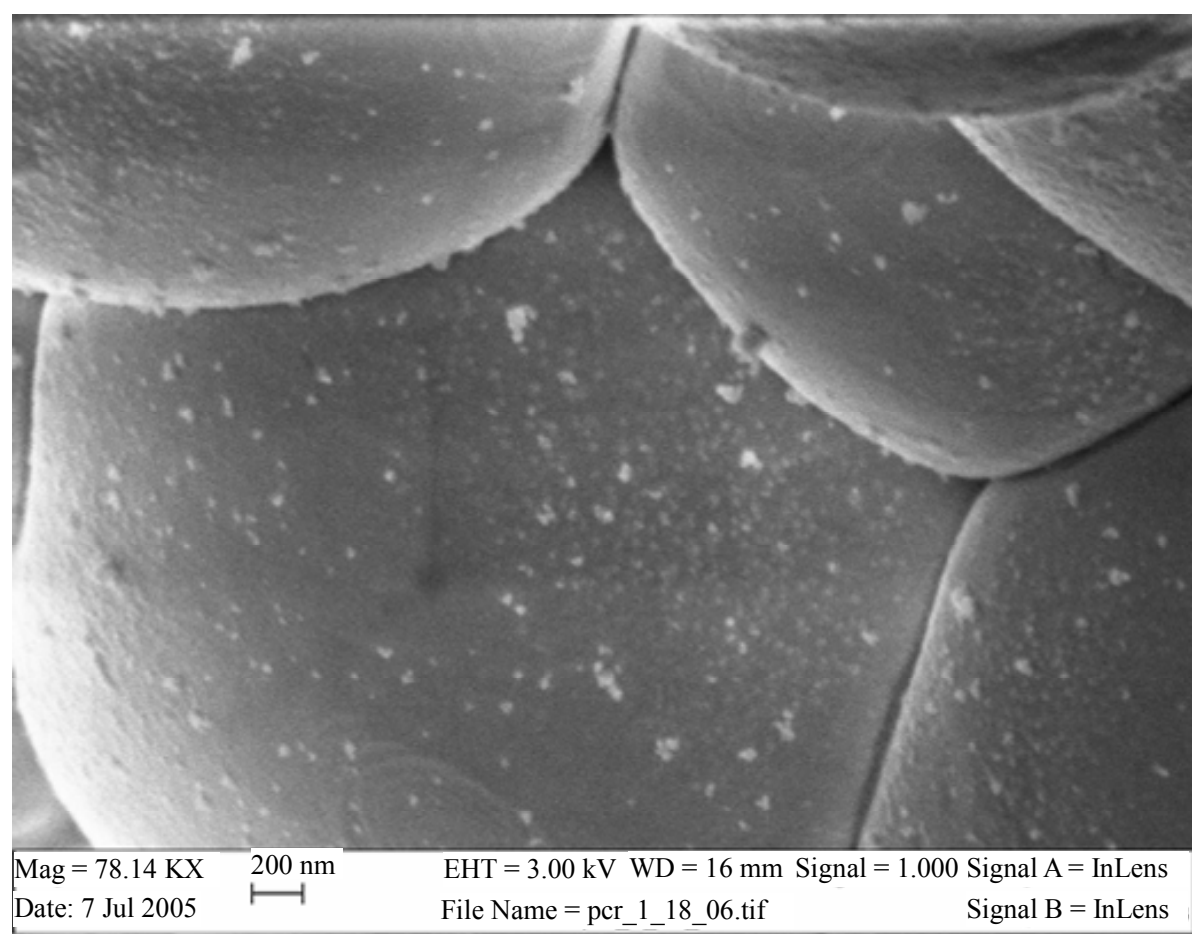

Figure 9. SEM micrograph of internal surface of closed pore in PZT piezoceramics covered by Pd nanoparticles.

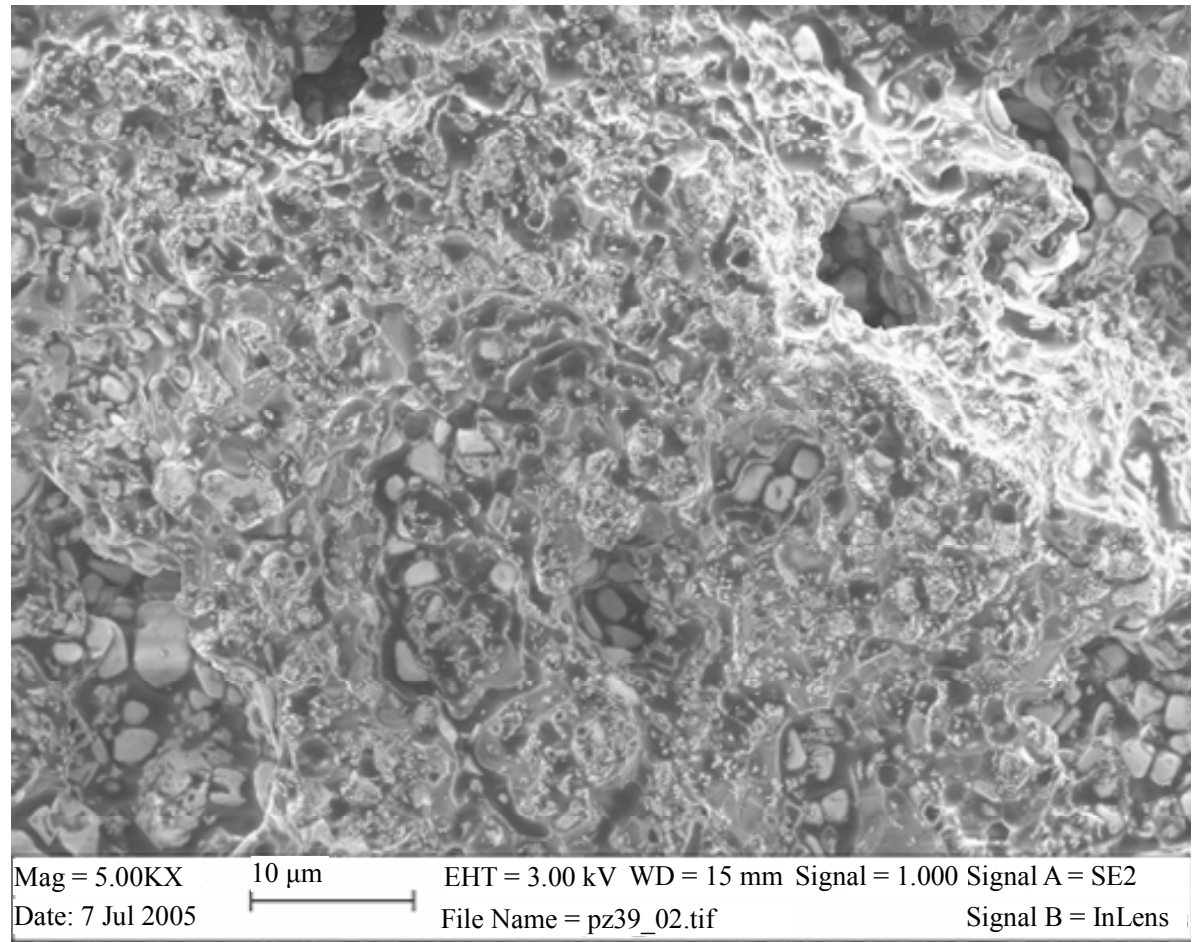

Figure 10. SEM micrograph of internal surface of closed pore in lead titanate piezoceramics covered by Ni nanoparticles layer.

It can be seen from the Figure 11 that the electromechanical activity of porous ceramics (difference between resonant $f_{r}$ and antiresonant frequency $f_{a}$ ) grows with the relative porosity $\mathrm{P}$ increase.
Table 1 shows dielectric and piezoelectric properties of lead metaniobate $\left(\mathrm{PbNb}_{2} \mathrm{O}_{6}\right)$ and lead potassium niobate $\left((\mathrm{Pb}, \mathrm{K}) \mathrm{Nb}_{2} \mathrm{O}_{6}\right)$ nanoporous piezoceramics. It is obvious that the nanoporous ceramics technology results in 


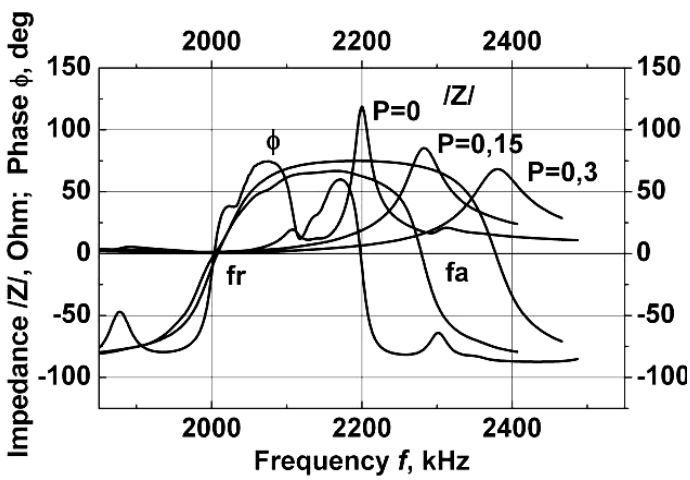

Figure 11. Impedance spectra for nanoporous PZT piezoceramics at different relative porosity $P$.

Table 1. Dielectric and piezoelectric properties of $\mathrm{PbNb}_{2} \mathrm{O}_{6}$ and $(\mathrm{Pb}, \mathrm{K}) \mathrm{Nb}_{2} \mathrm{O}_{6}$ nanoporous piezoceramics.

\begin{tabular}{|c|c|c|}
\hline Parameter/Material & $\begin{array}{l}\mathrm{PbNb}_{2} \mathrm{O}_{6} \\
\mathrm{P}=15 \%\end{array}$ & $\begin{array}{c}(\mathrm{Pb}, \mathrm{K}) \mathrm{Nb}_{2} \mathrm{O}_{6} \\
\mathrm{P}=15 \%\end{array}$ \\
\hline $\begin{array}{l}\text { Electromechanical coupling factor } \\
\text { for planar mode, } \mathrm{k}_{\mathrm{p}}\end{array}$ & 0 & 0 \\
\hline $\begin{array}{l}\text { Electromechanical coupling factor } \\
\text { for thickness mode, } \mathrm{k}_{\mathrm{t}}\end{array}$ & 0.42 & 0.45 \\
\hline Piezoelectric modulus, $\mathrm{d}_{33}\left(10^{-12}\right), \mathrm{C} / \mathrm{N}$ & 75 & 90 \\
\hline Dielectric constant, $\varepsilon_{33}{ }^{\mathrm{T}} / \varepsilon_{0}$ & 160 & 160 \\
\hline Dielectric loss $\tan , \tan \delta, \%$ & 0.6 & 0.8 \\
\hline $\begin{array}{l}\text { Mechanical quality factor for } \\
\text { thickness mode, } \mathrm{Q}_{\mathrm{M}}{ }^{\mathrm{t}}\end{array}$ & $<10$ & $<10$ \\
\hline Density, $\rho\left(10^{3}\right), \mathrm{g} / \mathrm{cm}^{3}$ & 5.7 & 5.6 \\
\hline Curie temperature, $\mathrm{T}_{\mathrm{C}},{ }^{\circ} \mathrm{C}$ & 560 & 550 \\
\hline Frequency constant, $\mathrm{N}_{\mathrm{t}}, \mathrm{kHz} \cdot \mathrm{mm}$ & 1300 & 1380 \\
\hline
\end{tabular}

increasing of piezoelectric anisotropy, removal of internal mechanical stress, increasing of mechanical durability, preventing of cracking and finally, allows production of stable in time elements of such "technologically difficult" ceramics as lead metaniobate with excellent and reproducible properties.

Dielectric and piezoelectric parameters of piezoceramic-metal nanoporous CMPC (lead titanate piezoceramics with closed nanoporous covered by Ni nanoparticles layers) are shown in Table 2.

We can see from Table 1 that electromechanical and piezoelectric activity as well as dielectric constant of nanoporous CMPC "piezoceramic-metal" increase with relative porosity, and consequently with metal content grows. This behavior is in good conformity with the theoretical and FEM modeling results [12,24,25] predicting grows of dielectric constant and piezoelectric modulus in the vicinity of dielectric-metal percolation threshold. The electromechanical behavior of CMPC with hollow metal spheres (pore with metalized internal
Table 2. Piezoelectric properties of piezoceramic-metal nanoporous CMPC.

\begin{tabular}{|c|c|c|}
\hline Parameter/Material & $\begin{array}{l}\mathrm{PbTiO}_{3} / \mathrm{Ni} \\
\mathrm{P}=20 \%\end{array}$ & $\begin{array}{c}\mathrm{PbTiO}_{3} / \mathrm{Ni} \\
\mathrm{P}=40 \%\end{array}$ \\
\hline $\begin{array}{l}\text { Electromechanical coupling factor } \\
\text { for planar mode, } \mathrm{k}_{\mathrm{p}}\end{array}$ & 0 & 0 \\
\hline $\begin{array}{l}\text { Electromechanical coupling factor } \\
\text { for thickness mode, } k_{t}\end{array}$ & 0.55 & 0.6 \\
\hline Piezoelectric modulus, $\mathrm{d}_{33}\left(10^{-12}\right), \mathrm{C} / \mathrm{N}$ & 150 & 275 \\
\hline Dielectric constant, $\varepsilon_{33}{ }^{\mathrm{T}} / \varepsilon_{0}$ & 250 & 480 \\
\hline Dielectric loss $\tan , \tan \delta, \%$ & 2 & 4 \\
\hline $\begin{array}{l}\text { Mechanical quality factor } \\
\text { for thickness mode, } Q_{M}{ }^{t}\end{array}$ & $<12$ & $<10$ \\
\hline Density, $\rho\left(10^{3}\right), \mathrm{g} / \mathrm{cm}^{3}$ & 6.4 & 4.8 \\
\hline Curie temperature, $\mathrm{T}_{\mathrm{C}},{ }^{\circ} \mathrm{C}$ & 490 & 480 \\
\hline Frequency constant, $\mathrm{N}_{\mathrm{t}}, \mathrm{kHz} \cdot \mathrm{mm}$ & 1200 & 800 \\
\hline
\end{tabular}

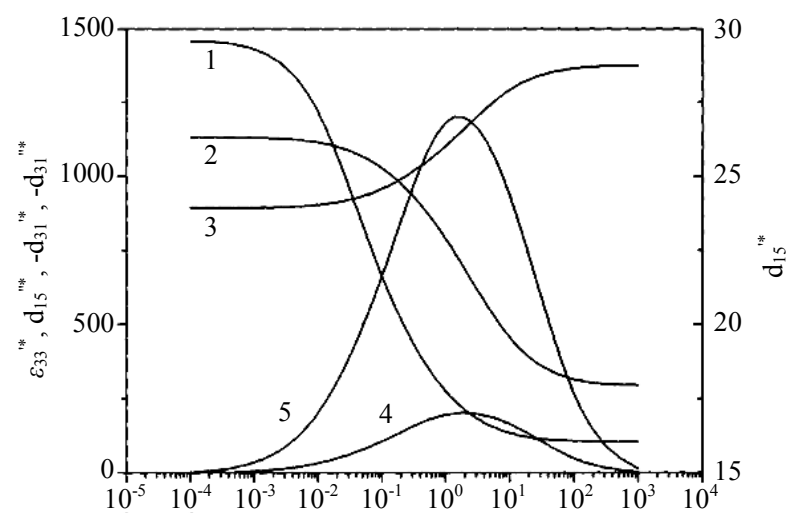

Figure 12. Frequency dependencies of real parts of dielectric constants $\varepsilon_{33} /^{*}(1)$, piezoelectric moduli $-d_{31} l^{*}, 10-14$ $\mathrm{C} / \mathrm{N}(2), d_{15} l^{*}, 10-12 \mathrm{C} / \mathrm{N}(3)$, as well as imaginary parts of $-d_{31} / /^{*}, 10-14$ C/N (4), $d_{15} / / *, 10$ - 15 C/N (5) for CMPC.

surface) is drastically differs from the solid metal sphere case, because of practically infinite elastic compliance of pores.

Preliminary experiments on nanoporous CMPC "piezoceramic-metal" in low frequency range $10^{-6}-10^{4} \mathrm{~Hz}$ confirmed also the theoretical predictions of giant dielectric relaxation and giant piezoelectric effect resulting from Maxwell-Wagner relaxation (Figure 12), as was foreshown in $[24,25]$.

New generation of nano- and microporous piezoceramics, and ceramic matrix piezocomposites with unique chemical and electromechanical properties can be usefull for a variety of ultrasonic transducers, sensors and actuators applications.

\section{REFERENCES}

[1] N. Setter, "Piezoelectric Materials in Devices," Swiss 
Institute of Technology, Switzerland, 2002, pp. 1-518.

[2] A. N. Rybjanets, A. V. Nasedkin and A. V. Turik, Integrated Ferroelectrics, Vol. 63, 2004, pp. 179-182. doi:10.1080/10584580490459404

[3] P.-H. Xiang, X.-L. Dong, H. Chen, Z. Zhang and J.-K. Guo, Ceramics International, Vol. 29, 2003, pp. 499-503. doi:10.1016/S0272-8842(02)00193-1

[4] A. N. Rybianets, Ferroelectrics, Vol. 360, 2007, pp. 8489. doi:10.1080/00150190701516210

[5] A. N. Rybyanets, "Ceramic Piezocomposites: Modeling, Technology, and Characterization,” In: I. A. Parinov Ed., Piezoceramic Materials and Devices, Nova Science Publishers Inc., New York, 2010, pp. 113-174.

[6] M. Donbrow, "Microcapsules and Nanoparticles in Medicine and Pharmacy," CRC Press, London, 1992, pp. 1368.

[7] S. P. Gubin, "Magnetic Nanoparticles," Willey-VCH, Manheim, 2009, pp. 1-283.

[8] S. P. Gubin, G. Yu Yurkov, M. S. Korobov, et al., Acta materialia, Vol. 53, 2005, pp. 1407-1413. doi:10.1016/j.actamat.2004.11.033

[9] S. P. Gubin, G. Yu. Yurkov and N. A. Kataeva, Inorganic Materials, Vol. 41, 2005, pp. 1017-1032. doi:10.1007/s10789-005-0255-1

[10] A. N. Rybjanets, O. N. Razumovskaja, L. A. Reznitchenko, V. D. Komarov and A. V. Turik, Integrated Ferroelectrics, Vol. 63, 2004, pp. 197-200. doi:10.1080/10584580490459468

[11] T. R. Shrout, W. A. Shulze and J. V. Biggers, Materials Research Bulletin, Vol. 14, 1979, pp. 1553-1559.

[12] A. N. Rybyanets, IEEE UFFC, Vol. 58, 2011, pp. 14921507.

[13] A. N. Rybyanets and A. A. Rybyanets, IEEE UFFC, Vol.
58, 2011, pp. 1757-1774. doi:10.1109/TUFFC.2011.2013

[14] "IEEE Standard on Piezoelectricity," ANSI/IEEE Std., 1987, p. 176.

[15] M. Alguero, C. Alemany, L. Pardo and A. M. Gonzalez, Journal of the American Ceramic Society, Vol. 87, 2004, pp. 209-212. doi:10.1111/j.1551-2916.2004.00209.x

[16] R. Holland, IEEE Transaction on Sonics Ultrason, Vol. SU-14, 1967, pp. 18-24. doi:10.1109/T-SU.1967.29405

[17] S. Sherrit, H. D. Wiederick and B. K. Mukherjee, Ferroelectrics, Vol. 134, 1992, pp. 111-115. doi:10.1080/00150199208015574

[18] S. Sherrit, H. D. Wiederick and B. K. Mukherjee, SPIE Proceedinqs of Ultrasonic Transducer Engineerinq, Vol. 3037, 1997, pp. 158-163. doi:10.1117/12.271326

[19] S. Sherrit, H. D. Wiederick and B. K. Mukherjee, SPIE Proceedings of Smart Materials, Structures, and Integrated Svstems, Vol. 3241, 1997, pp. 327-333.

[20] J. G. Smits, IEEE Transactions on Sonics and Ultrasonics, Vol. SU-23, 1976, pp. 393-402. doi:10.1109/T-SU.1976.30898

[21] PRAP, "Piezoelectric Resonance Analysis Program," TASI Technical Software Inc. www.tasitechnical.com

[22] A. N. Rybianets and A. V. Nasedkin, Ferroelectrics, Vol. 360, 2007, pp. 57-62. doi:10.1080/00150190701516020

[23] A. N. Rybianets and R. Tasker, Ferroelectrics, Vol. 360, 2007, pp. 90-95. doi:10.1080/00150190701516228

[24] S. A. Turik, L. A. Reznitchenko, A. N. Rybjanets, S. I. Dudkina, A. V. Turik and A. A. Yesis, Journal of Applied Physics, Vol. 97, 2005, Article ID: 064102. doi:10.1063/1.1861965

[25] A. V. Turik, A. I. Chernobabov, G. S. Radchenko and S. A. Turik, Journal of Physics C: Solid State Physics, Vol. 46, 2004, pp. 2139-2142. 